\title{
Factors Affecting Body Temperatures of Toads
}

\author{
Cynthia Carey* \\ Division of Biological Sciences, The University of Michigan, Ann Arbor, MI 48109, USA
}

\begin{abstract}
Summary. Factors influencing levels and rates of variation of body temperature $\left(T_{b}\right)$ in montane Bufo boreas boreas and in lowland Bufo boreas halophilus were investigated as an initial step toward understanding the role of natural thermal variation in the physiology and energetics of these ectothermic animals. Body temperatures of boreas can vary $25-30^{\circ} \mathrm{C}$ over $24-\mathrm{h}$ periods. Such variation is primarily due to both nocturnal and diurnal activity and the physical characteristics of the montane environment. Bufo boreas halophilus are primarily nocturnal except during breeding and are voluntarily active at body temperatures ranging between 10 and $25^{\circ} \mathrm{C}$. Despite variation in $T_{b}$ encountered in the field, boreas select a narrow range of $T_{b}$ in a thermal gradient, averaging 23.5 and $26.2^{\circ} \mathrm{C}$ for fasted individuals maintained under field conditions or acclimated to $20^{\circ} \mathrm{C}$, respectively. In a thermal gradient the mean $T_{b}$ of fasted halophilus acclimated to $20^{\circ} \mathrm{C}$ is $23.9^{\circ} \mathrm{C}$. Skin color of boreas varies in the field from very dark to light. The dark skins absorb approximately $4 \%$ more radiation than the light ones. Light colored boreas should absorb approximately $5 \%$ more radiation than similarly colored halophilus. Evaporative water losses increase directly with skin temperatures and vapor pressure deficit in both subspecies. Larger individuals heat and cool more slowly than smaller ones. Calculation of an enery budget for boreal toads suggests that they could sit in direct sunlight for long periods without fatally overheating, providing the skin was continually moist.
\end{abstract}

\section{Introduction}

Variations in body temperature $\left(T_{b}\right)$ are undoubtedly an important factor in the biology of ectothermic animals since $T_{b}$ affects not only the kinetics of biochemical and physiological processes but also the rate at which energy and materials can be extracted from the environment and used for maintenance, growth, and reproduction. Under appropropriate conditions many terrestrial

* Present address: Department of EPO Biology, University of Colorado, Boulder, CO 80309, USA 
ectotherms can stabilize $T_{b}$ for certain periods by behavioral means (Cowles and Bogert, 1944; Brattstrom, 1963; Heath, 1965; Licht et al., 1966; DeWitt, 1967a, b; Bradshaw and Main, 1968; Lillywhite, 1971; Lillywhite et al., 1973; Gatten, 1974). However, most terrestrial ectotherms are exposed to some, if not substantial, daily and seasonal variation in $T_{b}$ due to behavioral choice (Brett, 1971) or variation in ambient temperature $\left(T_{a}\right)$. The precise effect of such variation on the physiology and energetics of an ectothermic species is currently difficult to define for two reasons. First, detailed information on the extent and rapidity of daily and seasonal variation of $T_{b}$ is lacking for most species and second, the extent to which the physiological responses of laboratory acclimated animals to variation in $T_{b}$ accurately reflect responses of similar individuals exposed to natural thermal variation is not clear.

Since $T_{b}$ is a complex integration of behavior, physiology, morphology and characteristics of the physical environment of the animal (Bartlett and Gates, 1967; Norris, 1967; Porter and Gates, 1969; Tracy, 1972; Porter et al., 1973; Tracy, 1975; Bakken and Gates, 1975; Bakken, 1976b), an initial step in understanding the effect of thermal variation on the physiology and energetics of an ectothermic species is to document the fluctuations of the ambient environment and the particular properties of the group which might affect the range and rapidity of fluctuations of $T_{b}$. Since the implications of fluctuating $T_{b}$ might be especially interesting in a species living in a habitat characterized by extensive daily and seasonal variations in ambient temperature, the particular group chosen for this study is the boreal toad, Bufo boreas boreas. It is a member of a widely distributed form with populations ranging from sea level to over $3550 \mathrm{~m}$ in western North America (Campbell, 1970). At the upper altitudinal reaches of its distribution, the high transparency and low density of mountain air provide little attentuation of solar insolation during the day and foster large radiational losses of heat at night. These factors combine to produce wide daily fluctuations in substrate and ambient temperature. Bufo boreas halophilus, a lowland relative occupying a thermally less variable habitat, is included for comparison. The physiological and energetic consequences of the variations in $T_{b}$ encountered by these two groups will be addressed in subsequent papers.

\section{Materials and Methods}

\section{Solar and Thermal Characteristics of the Montane Environment}

Air temperatures and solar radiation were monitored at ground level $(0.2 \mathrm{~m})$ at the Rocky Mountain Biological Laboratory (RMBL), Gothic, Gunnison County, Colorado (elevation $2900 \mathrm{~m}$ ), in JuneAugust, 1973. Air temperatures were recorded by a hygrothermograph (Bendix Corp.) appropriately shielded from sunlight in a ventilated shelter. Intensity of solar radiation was registered by a recording pyranometer (Beaufort Instruments).

\section{Body Temperatures of Active Toads}

Bufo b. boreas were captured in the East River valley near RMBL between May and August, 1971-1975. They were collected in moist, grassy areas around beaver ponds or streams at altitudes 
between 3000 and $3355 \mathrm{~m}$. Bufo boreas halophilus were captured in March of 1972-1974 at the Devil's Gate Reservoir, La Canada, Los Angeles County, California. In the following discussion "boreas" will designate the nominate subspecies, Bufo b. boreas, and "halophilus" will designate the subspecies Bufo boreas halophilus.

The $T_{b}$ of each toad was measured orally immediately after capture with a suitably calibrated small animal thermistor (time constant $=3.6 \mathrm{~s}$ ) connected to a YSI telethermometer. The thermistor was inserted $2-4 \mathrm{~cm}$ into the esophagus, the exact distance depending on the size of the toad. The animal was grasped by the legs to minimize heat exchange with the fingers of the investigator. To determine whether grasping the animal in this manner affected the measurement, a thermocouple connected to a Honeywell-15 multipoint recording potentiometer was implanted near the heart in the body cavity of an anesthetized, 40-g toad. After the toad had come to thermal equilibrium in a refrigerator at $8^{\circ} \mathrm{C}$ and had recovered from the anesthetic, its $T_{b}$ was taken orally with the thermistor by the same method used in the field. The time required for this measurement (5-10 s) left unchanged the deep $T_{b}$ measured by the thermocouple. Therefore, this temperature was reflected adequately by the oral value.

Following determination of $T_{b}$, the air temperature $\left(T_{a}\right)$ at the place where the toad was picked up was measured at ground level by a shaded YSI air probe. The temperature of the substrate $\left(T_{\text {sub }}\right)$ was recorded with the small animal probe by inserting it $2-3 \mathrm{~mm}$ beneath the surface of the soil or water.

\section{Telemetry of Body Temperatures of Bufo b. boreas}

The $T_{b}$ of six adult boreas, intensity of solar radiation, $T_{a}, T_{s u b}$, and wind speed were measured for 24-h periods between late June and early August. The $T_{b}$ was transmitted by a radiotransmitter (Mini-Mitter, Inc., Indianapolis, Indiana) which was $9 \mathrm{~mm}$ wide, $11 \mathrm{~mm}$ long, and weighed $2.4 \mathrm{~g}$. It was calibrated in a water bath against a mercury thermometer which had been previously calibrated against a Bureau of Standards thermometer. To test whether the time constant of the telemetry device was sufficiently short to permit accurate tracking of $T_{b}$ during heating and cooling, a copper-constantan thermocouple and the telemetry device were implanted in the abdomen of a 46-g anesthetized toad in such a manner that they registered $T_{b}$ from the same region. The toad was transferred to a refrigerator following recovery from anesthesia. The rate of cooling recorded from the thermocouple with a Honeywell-16 recording potentiometer was similar to that indicated by the transmitter. The observed rate of cooling was faster than the rates noted in the field. The telemetry device was therefore judged to track changes in $T_{b}$ accurately in the field. No hysteresis was noted when calibration curves for warming or cooling were compared. The transmitter, tested before and after each implantation in a toad, exhibited no drift in calibration. The transmitter was placed in the body cavity of a toad via a ventral incision after anesthesia with $2 \%$ tricaine methanesulfonate $(1.0 \mathrm{ml} / 100 \mathrm{~g}$ body mass $)$. Toads were not used for the telemetry study unless they were active and alert following surgery.

Approximately $48-72 \mathrm{~h}$ after implantation of the transmitter, the toad was placed in a $2.5 \times 2.5 \mathrm{~m}$ enclosure of $0.5 \mathrm{~m}$ screen fence located near a beaver pond at $3050 \mathrm{~m}$ altitude. The toad had access within the enclosure to areas exposed to sunlight during the day, shade provided by willows (Salix) and a small spruce (Picea), and standing water from a small spring. The area in the enclosure resembled the moist substrate upon which the toads were typically captured. Measurements were recorded approximately $15 \mathrm{~m}$ from the enclosure so that the toad was not disturbed for the duration of the test. An antenna of copper wire was strung in parallel loops at $10 \mathrm{~cm}$ intervals on a wooden frame placed on the ground in the enclosures. Signals from the transmitter were picked up by the antenna and transferred by coaxial cable to the antenna of a battery powered AM radio. Substrate temperatures in an unshaded area of the enclosure were recorded by a small animal thermistor placed $1-2 \mathrm{~mm}$ beneath the surface of the soil and connected by a long lead to a YSI telethermometer. Wind speed measured by a microcup $(2.5 \mathrm{~cm})$ impulse anemometer (Rauchfuss Instruments) mounted $3-4 \mathrm{~cm}$ above the ground in the enclosure. Air temperatures at $1 \mathrm{~cm}$ were measured by a shaded YSI probe. Solar radiation was read directly from a pyranometer located in the sun $15 \mathrm{~m}$ from the enclosure.

Each toad was placed in the enclosure between 1800-2000 h. Recordings of $T_{b}$ and environmental data began $0630 \mathrm{~h}$ the next morning and continued every $30 \mathrm{~min}$ until direct sunlight reached the enclosure at approximately $0800-0830 \mathrm{~h}$ (MTD). Between 0800 und $2000 \mathrm{~h}$, readings were taken 
every $5 \mathrm{~min}$, between 2000 and 2200 every $30 \mathrm{~min}$, and between 2200 and 0630 approximately every $2 \mathrm{~h}$.

Two 24-h experiments tested the possibilities that confinement in the enclosure or implantation of the telemetry device altered the behavior of experimental toads. Two toads without implanted transmitters were released, one into a second enclosure similar to the one used for telemetry and the other into an adjacent marshy area. Body temperatures were taken orally approximately every $2 \mathrm{~h}$. Temperatures recorded for these toads were compared with telemetered $T_{b}$ of a third toad tested concurrently in the regular enclosure.

\section{Thermal Preference}

Selection of body temperatures by eight adult boreas in a thermal gradient was measured in June, $1973-74$, at RMBL. The toads, with a mean body mass of $32.8 \mathrm{~g}$ (range $30.2-49.8 \mathrm{~g}$ ), were captured near Gothic, Colorado, and housed under natural conditions of light and temperature. Additionally, temperature preferences of six boreas and eight halophilus acclimated to $20^{\circ} \mathrm{C}$ and a $12 \mathrm{~h} \mathrm{~L} / \mathrm{D}$ photoperiod for at least one month were measured at The University of Michigan. The boreas were tested in August and September, 1973, and the halophilus in May 1972. Mean body masses of the acclimated animals were 34.5 and $41.2 \mathrm{~g}$ for boreas and halophilus, respectively. Male and female toads did not have significantly different $T_{b}$, so their values have been pooled for each subspecies.

A thermal gradient was constructed from a galvanized steel trough $2.8 \mathrm{~m}$ long, $0.4 \mathrm{~m}$ high, and $0.2 \mathrm{~m}$ wide. The apparatus was placed in a controlled temperature room at $10^{\circ} \mathrm{C}$, which set the lower limit of the gradient. The upper temperature of the gradient, $43^{\circ} \mathrm{C}$, was produced by a heat lamp positioned over the trough. A linear increase in temperature from the cold end was achieved by winding electrical heating tape from side to side in the trough in a zigzag pattern of increasing narrowness as the warm end under the heat lamp was approached. The floor of the trough was covered with $3 \mathrm{~cm}$ of peat moss saturated with water. The tape was completely covered by the peat moss, but toads often burrowed through the moss to sit directly on it. Water was added approximately every $12 \mathrm{~h}$ to keep the moss fully saturated. An overhead fluorescent lamp was turned on for $12 \mathrm{~h}$ each day. The heat lamp remained on at all times during the test.

About $24 \mathrm{~h}$ before a test, a toad which had been fasted for $6-8$ days was anesthetized with $2 \%$ tricaine methanesulfonate. A previously calibrated 36-ga copper-constantan thermocouple was sewn into a dorsal incision in the back. The thermocouple was inserted about $2 \mathrm{~cm}$ into the body cavity between the lung and the viscera so that it registered $T_{b}$ near the heart, with placement later confirmed by dissection. The fasted toad was placed in the trough at $0900 \mathrm{~h}$ and was undisturbed for the next $24 \mathrm{~h}$ except at $2100 \mathrm{~h}$ when water was added to the peat moss. At $0900 \mathrm{hr}$ the next morning, the toad was force fed a meal of crickets equal to $1-2 \%$ of its body mass and replaced in the gradient for another $24 \mathrm{~h}$. The meal size was selected because it equaled the mean mass of stomach contents of boreas in the field, corrected for the mass of digestive fluid (Carey, unpubl. data). Every $30 \mathrm{~s}$ body and substrate temperatures, measured by thermocouples placed in the peat moss every $0.4 \mathrm{~m}$, were recorded to the nearest $0.1^{\circ} \mathrm{C}$ by a Honeywell-16 recording potentiometer. The toads usually wandered within the gradient for several hours following introduction into the trough and then settled in one location for the duration of he test. Body temperatures recorded during the initial period were omitted from consideration in determining the preferred $T_{b}$. Once the toad settled down, $T_{b}$ recorded at 30- to 45 -min intervals were taken from the potentiometer record. Ten to 30 records from each animal in both the fasted and fed condition were averaged to determine the preferred temperature of each subspecies and the effect of feeding on the preferences. Mean values were compared with a non-parametric Bayseian posterior probability test (Lindley, 1965), because assumptions of normality and equality of variances did not hold for these data. Statistical significance was assumed if $P<0.01$.

To test whether implantation of the thermocouples altered the preferred temperatures, 10 unfed boreas, housed under natural conditions at RMBL, were placed individually in the trough for $24 \mathrm{~h}$. Oral $T_{b}$ were measured with a YSI telethermometer at $6 \mathrm{~h}$ intervals.

The possibility existed that the $T_{b}$ selected by toads during the second 24-h period might reflect greater familiarity with the chamber containing the thermal gradient rather than the effect of feeding on preferred temperature (see Heath, 1965). To test this, two unfed toads were tested 
in the gradient for $48 \mathrm{~h}$ each, with interruptions only every $12 \mathrm{~h}$ for addition of water to the peat moss.

\section{Effects of Color Change on Absorption of Radiation}

The skin color of boreas in the field varies from a dark brown to a light, creamy color. Dark colors are most often associated with toads at cooler $T_{b}$ and light colors with toads at warmer $T_{b}$. Live toads were tested to determine if this variation in color could affect absorption of solar radiation.

Reflectance of wavelengths of $290-2600 \mathrm{~nm}$ by skins of live boreas was measured by a Beckman DK-2A dual beam, ratio-recording spectroreflectometer. Principles underlying the operation of the Beckman DK-2A for tests such as this are reviewed by Porter (1967).

Individual toads were immobilized by strapping them with electrical tape onto an aluminum block similar to that illustrated in Norris (1967). The $T_{b}$ of the toad could be regulated by pumping water from thermostatically controlled water baths or ice baths through the block. Skin color of boreas was unaffected by short-term changes in $T_{b}$ or electrical stimulation, methods which have been employed successfully to achieve color change and maximum blanching of reptiles (Norris, 1967; Porter, 1967). However, color change in these toads can be induced in the laboratory by maintaining them at cold or warm temperatures. Two dark toads, freshly captured in Colorado and held for 2 weeks at $10^{\circ} \mathrm{C}$, were compared with two light toads acclimated to $30^{\circ} \mathrm{C}$ for 2 months. While the color of skins of these toads may not represent the absolute extremes of blanching or darkening possible for this species, the colors were quite distinct visually from each other and similar to observed differences in the field. After a toad was mounted on the aluminium block, a quartz disc, used to prevent light leaks and contamination of the integrating sphere, was tightly pressed on the back to one side of the spinal cord and fastened into place with black electrical tape. The block was mounted on the spectrophotometer in a way that the quartz disc fitted directly over the sample port. A similar quartz disc was placed over the reference slide covered with $\mathrm{BaSO}_{4}$.

Ninety-seven reflectance values for each toad extracted from the spectroreflectometer record at prescribed intervals and were used in conjunction with the program devised by McCullough and Porter (1971) to calculate average absorption of solar radiation specific for the altitude and geographical location where the toads normally live.

Color change in halophilus is not as evident in the field as in boreas and cannot readily be induced by exposure to constant low or warm temperatures in the laboratory. One individual with a typical creamy, greenish skin was tested for comparison with the values for the montane species.

\section{Relation of Evaporative Water Loss to Temperature}

Evaporative water loss (EWL) of 40 to $60 \mathrm{~g}$ boreas and halophilus was measured in a system to be described in greater detail by Bakken (MS in prep.). Six animals of each subspecies were tested individually at The University of Michigan. Each was used only once at each test temperature. The toads were acclimated to $20^{\circ} \mathrm{C}$ for at least two weeks and starved for 4 days before testing.

The system consisted of a $20 \times 10 \times 13 \mathrm{~cm}$ chamber with two of the sidewalls and a detachable roof made of hollow Plexiglas. A metal pan covered with a wire screen and filled with mineral oil to catch urine served as a floor. The floor and wall temperatures were regulated near 10 , 20 , or $30^{\circ} \mathrm{C}$ by circulating water through the hollow Plexiglas from a temperature regulated water bath. The end walls of the chamber consisted of baffles constructed from horizontally placed plastic soda straws, $2 \mathrm{~cm}$ in length. All walls were painted non-reflective black. The sides and floor of the animal chamber and small fans for creating movement of air were enclosed in a temperature regulated, air-tight box. The roof of the chamber was flush with the top of the air-tight box. The fans recirculated the air, which was controlled at the same temperatures as the walls and roof of the chamber, into and out of the chamber through the baffles, producing essentially laminar flow $(5 \%$ turbulence). The wind speed, $60.8 \mathrm{~cm} / \mathrm{s}$, was selected because it fell approximately in the middle of the range measured at ground level $(3-4 \mathrm{~cm})$ in the field. It was measured before and after each experiment with a temperature compensated anemometer (Thermo-Systems, Inc., model $1054 \mathrm{~A}$, probe $1330-18-20$ ) connected to a TSI power supply, model 1051-2. 
Dry air was introduced into the recirculating system from a compressed gas cylinder. The rate of flow of air was measured by a model 2232 TSI mass flowmeter. Most of the air was recirculated and the rest vented to the exterior. The system was maintained at a pressure slightly above that of the outside by bubbling the excurrent air through $2 \mathrm{~cm}$ of oil. The dew point was regulated in the chamber in part by the rate of inflow of dry air and in part by passing a portion of the recirculated air through a drying tube. A solenoid, controlled by a dew point hygrometer (EG \& G Instruments, model 880 ), alternately routed the air leaving the animal through a Drierite $\left(\mathrm{CaSO}_{4}\right)$ filled drying tube, or a bypass which returned the air directly to the animal chamber. Water vapor pressure was accurately maintained at a relative humidity of $68-70 \%$ at the three temperatures tested. The water saturation deficit at this humidity varied from $3.68 \mathrm{mbar}$ at $10^{\circ} \mathrm{C}$ to $12.72 \mathrm{mbar}$ at $30^{\circ} \mathrm{C}$. When the dew point was successfully regulated, input of water into the system by evaporation from the animal constituted its EWL at that temperature and wind speed.

A toad was weighed on a Mettler P16ON top-loading balance after compressing the bladder to remove urine. Two copper-constantan thermocouples were inserted directly beneath the dorsal skin and glued into place with Permabond cement. One to $3 \mathrm{~h}$ were required for the water vapor pressure to reach the pre-set dew point and for the toad to become inactive. Then, drying tubes were weighed to the nearest $0.001 \mathrm{~g}$ on the Mettler balance and inserted into the recirculating air stream and at the excurrent air port. During each run of approximately $20-30 \mathrm{~min}$, the dew point, flow rate of dry air, and temperatures of skin, air, roof, and walls were recorded every 2 min on a Kaye (Systems 8000 ) recorder. The amount of water collected in the drying tubes was determined gravimetrically and the lowest value for mass of water collected in the drying tubes during 3 runs was used as the EWL for each animal. The behavior of the toad was observed with a one-way mirror. Data for EWL were discarded if a toad moved in the chamber during the test. After each test was complete, the toad was quickly removed from the chamber and body temperature taken orally with a YSI thermistor and telethermometer. The toad was then reweighed. Decrease in body mass during the run cannot be used as an estimate of EWL due to the long equilibration period prior to the tests.

\section{Relation of Rates of Heating and Cooling to Body Mass}

The effect of body mass on the rate of heating and cooling was measured in the same apparatus used for measurement of EWL. Toads (15.3-60.7 g body mass) were anesthetized with $2 \%$ tricaine methanesulfonate. A thermocouple, sheathed with protective polyethylene surgical tubing, was implanted in the body cavity through the back. It was inserted 1 to $3 \mathrm{~cm}$ between the lung and spinal column into the viscera and glued into place with Permabond cement. An additional thermocouple was implanted directly beneath the dorsal skin. Each anesthetized toad was placed in the chamber in a posture similar to that used by toads basking in the field. The limbs were placed close to the body and the head lowered over the forelimbs. The toads remained anesthetized during the test, and the posture was not altered. Respiratory and heart rates were not observed due to the depth of the anesthesia. Air, wall, and roof temperatures were controlled at $9.4 \pm 0.2^{\circ} \mathrm{C}$, $8.4 \pm 0.1^{\circ} \mathrm{C}$ and $8.4 \pm 0.1^{\circ} \mathrm{C}$, respectively. Dew point was regulated between 5 to $7.5^{\circ} \mathrm{C}$. The rate of inflow of dry air was increased during heating and decreased during cooling to maintain dew point within those values. The effective wind speed, set at $30.4 \mathrm{~cm} / \mathrm{s}$, would have been slightly faster for larger toads, since they occupied more than $10 \%$ of the cross-sectional area of the chamber (W.P. Porter, pers. comm.). When the deep body $T_{b}$ of the toad had approximately equilibrated with the surroundings, four Sylvania 500 Watt tungsten-halogen spotlights positioned $130 \mathrm{~cm}$ above the chamber were turned on. The radiation from these lamps passed through a $6 \mathrm{~cm}$ layer of water suspended in a Plexiglas box $1 \mathrm{~m}$ over the chamber and the Plexiglas roof of the chamber. The radiant heat load from the lamps was measured before and after each run with an Epply pyranometer, Model 8-48, connected to a Fluke $8000 \mathrm{~A}$ digital multimeter. The radiation was constant for all runs at $1.15 \mathrm{cal}\left(\mathrm{cm}^{2} \cdot \mathrm{min}\right)^{-1}$. Temperatures of the skin and core of the toad, air, wall, and roof and the dew point were recorded by the Kaye recorder. The lights were turned off when the $T_{b}$ of the toad neared an equilibrium temperature. The $T_{b}$ of the toad and environmental parameters were then recorded during cooling. Body temperatures extracted from the Kaye record for heating and cooling were analyzed using the program developed for this purpose by Bakken (1976a). 


\section{Results}

\section{Solar and Thermal Characteristics of the Montane Environment}

Maximal values for solar radiation on clear, cloudless days reach $1.4-1.5 \mathrm{cal}$ $\left(\mathrm{cm}^{2} \cdot \min \right)^{-1}$ (Fig. 1). Slightly higher values are recorded with scattered cloudiness due to reflection of solar radiation from the clouds. Periodic cloud cover results in highly variable levels of direct solar insolation reaching the ground on most days. Mountain peaks $(3050-3680 \mathrm{~m})$ on the eastern and western sides of the East River valley restrict the amount of direct solar insolation during the day. The intensity of solar insolation is already about $0.8-1.0 \mathrm{cal}\left(\mathrm{cm}^{2} \mathrm{~min}\right)^{-1}$ by the time of morning the sunlight reaches the floor of the valley, and some parts of the valley are shaded from direct sunlight by a mountain as early as $1600 \mathrm{~h}$ in the afternoon.

Maximal daytime air temperatures reach $15-23^{\circ} \mathrm{C}$ on totally or mostly sunny days. Air temperatures on clear nights fall near or below $0^{\circ} \mathrm{C}$. Cloud cover reduces daytime $T_{a}$ to between $10-15^{\circ} \mathrm{C}$, but accompanies higher nighttime temperatures ranging between 5 and $10^{\circ} \mathrm{C}$. Late spring snowstorms occurring in late May to mid-June in $1973-75$ produced daytime $T_{a}$ near $0^{\circ} \mathrm{C}$.

\section{Body Temperatures and Behavior of Active Bufo boreas boreas}

Activity of boreas in the fields is not confined to one phase of the daily period. After breeding in June, adults and juveniles (sexually immature, metamorphosed toads) are most often seen during the day in open, sunny, and moist areas near water. Orientation of the toads to the sun appears to be random. Toads sitting in the sun typically press the groin area onto moist substrate. Individuals rarely move more than a few meters during the day, long distance movements occurring primarily at night.

Body temperatures of toads are highly correlated with the extent of solar radiation. On clear days toads sitting in the sun have $T_{b}$ ranging from $22-33^{\circ} \mathrm{C}$, the exact temperature depending on the time of day. Temperatures of toads generally vary between 10 and $25^{\circ} \mathrm{C}$ on partly cloudy days, the exact values depending on the degree and frequency of cloud cover. At night the $T_{b}$ of toads approximate $T_{a}$ and $T_{\text {sub }}$, which are usually between 0 and $10^{\circ} \mathrm{C}$. On nights when $T_{a}$ drop below freezing, toads take cover under logs or submerge themselves under water. Several toads were caught between 0100 and $0200 \mathrm{~h}$ at night with frost on their backs and $T_{b}$ of $0.2^{\circ} \mathrm{C}$. The range of $T_{b}$ recorded was 0.2 to $33.9^{\circ} \mathrm{C}$ with a mean $\pm \mathrm{SE}$ for 296 measurements of $20.7 \pm 0.4^{\circ} \mathrm{C}$. Active males, females, and juveniles exhibited similar behavior and overlap in $\mathrm{T}_{b}$.

Oral $T_{b}$ of boreas are significantly $(P<0.01)$ correlated with both $T_{a}$ and $T_{\text {sub }}$ at the spot of capture (Fig. 2). Like $T_{b}$, levels of $T_{a}$ and $T_{s u b}$ are highly correlated with the extent of solar radiation. 


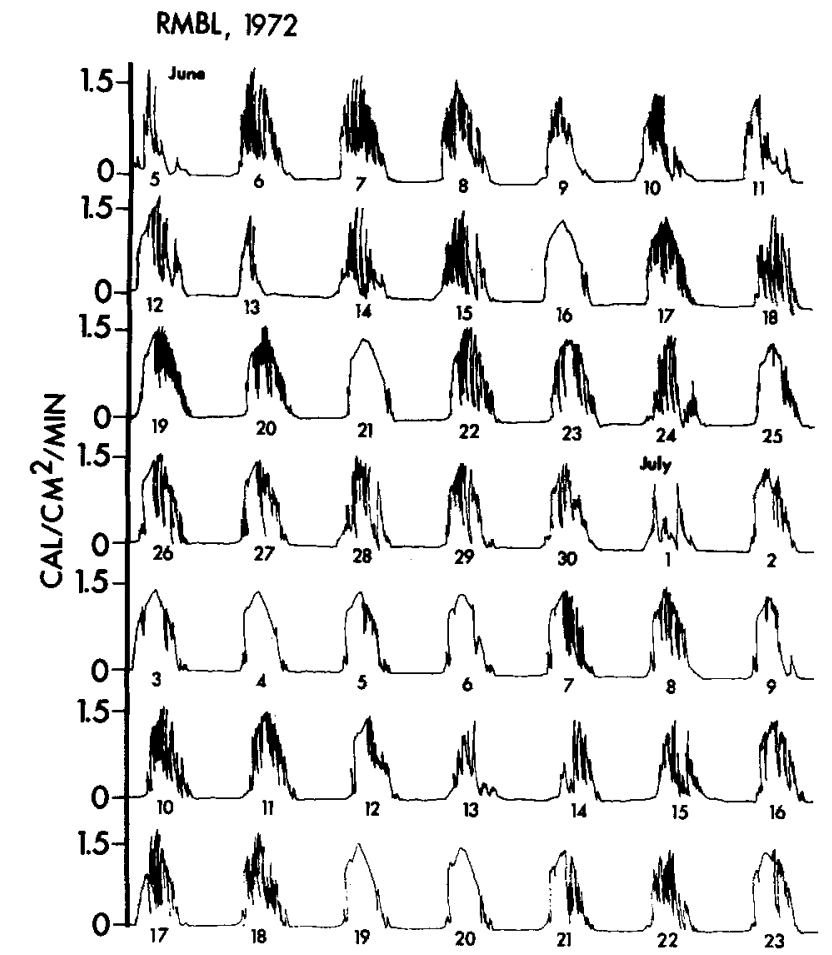

Fig. 1. Representative daily recordings of solar radiation for 5 June through 23 July 1972. Measurements were made at $2900 \mathrm{~m}$ near the Rocky Mountain Biological Laboratory, Gothic, Gunnison County, Colorado. Small numbers beneath each record denote day of month

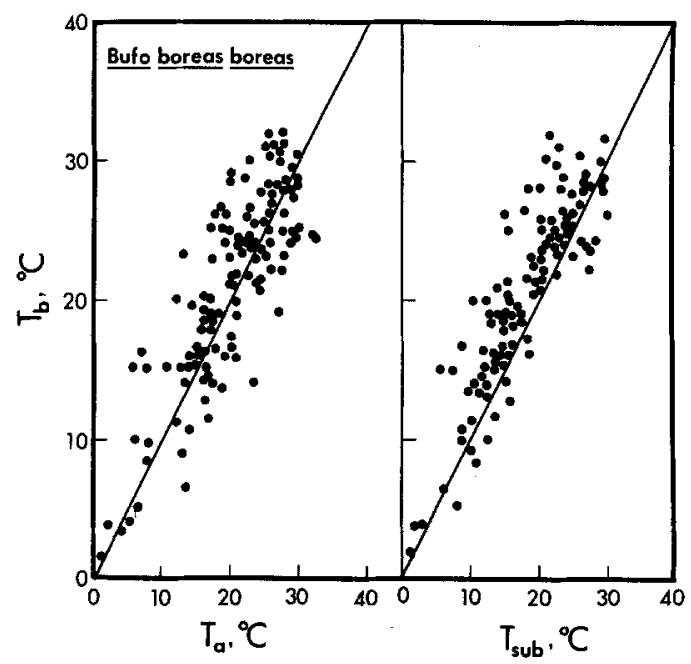

Fig. 2. The relations of oral body temperature $\left(T_{b}\right)$ of Bufo boreas boreas to air temperature $\left(T_{a}\right)$ measured at ground level and to substrate temperature $\left(T_{s u b}\right)$ at the point of capture of the toad. Measurements were made at $3050 \mathrm{~m}$ near Gothic, Gunnison County, Colorado. The data shown here represent only a portion of the total number of values collected, but the relation of $T_{b}$ to $T_{a}$ and $T_{s u b}$ shown by these data does not differ significantly from that of the total sample. The diagonal line in the middle of each graph marks equivalency between $T_{b}$ and $T_{a}$ or $T_{\text {sub. }}$. Correlation coefficients for all data for $T_{b}$ with $T_{a}$ and $T_{\text {sub }}$ equal 0.78 and 0.85 , respectively. The linear relation between $T_{b}$ and $T_{a}$ for all data is best described by the least squares regression: $T_{b}=4.5+0.825 T_{a}(n=276)$, and for the relation of $T_{b}$ to $T_{s u b}: T_{b}=8.17+0.656 T_{\text {sub }}(n=273)$, where all temperatures are in degrees Celsius. The slope of both equations differs significantly from 1 

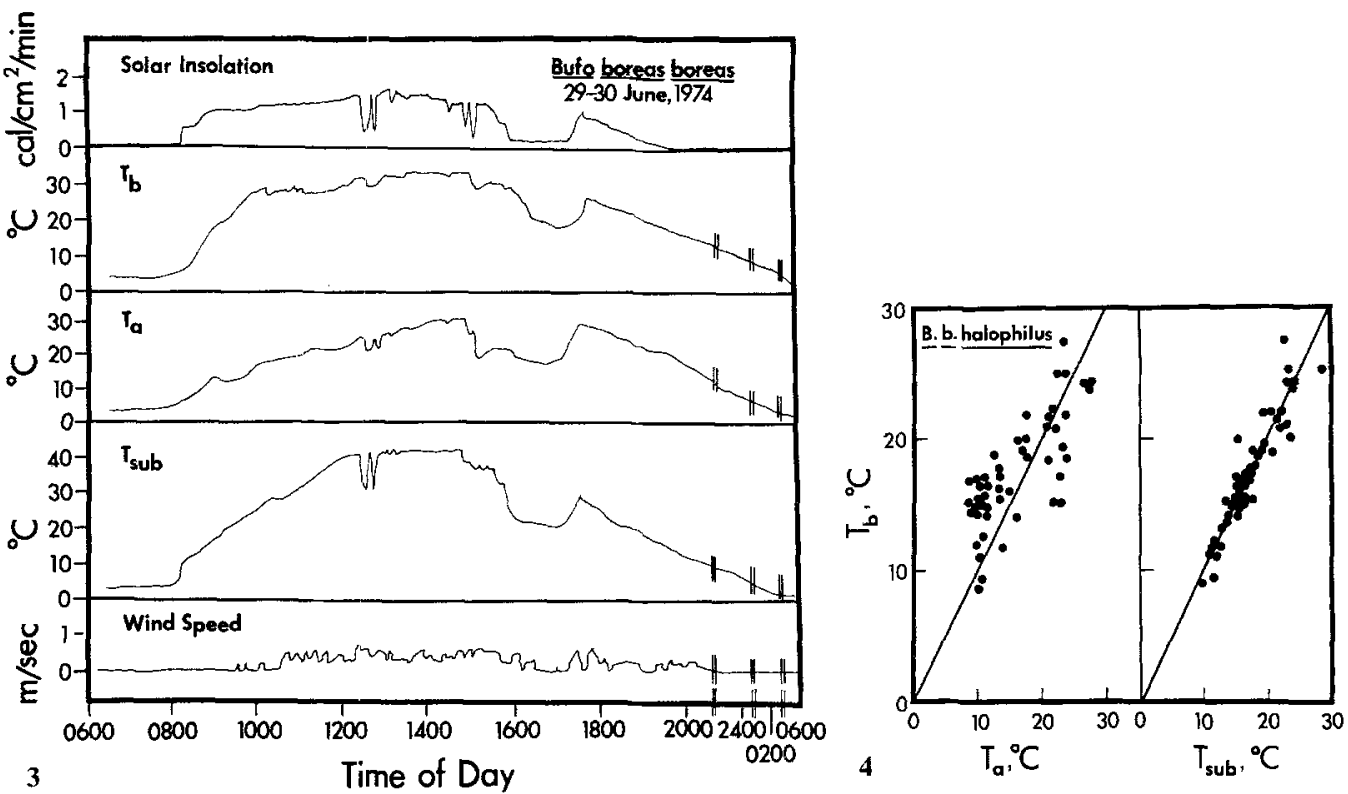

Fig. 3. Results of a typical 24-h measurement by telemetry of body temperature $\left(T_{b}\right)$ of an adult, 52.1 -g female Bufo boreas boreas in relation to solar insolation, ambient temperature $\left(T_{a}\right)$, substrate temperature $\left(T_{s u b}\right)$, and wind speed. Dips in the record of solar insolation during daylight hours indicate periodic cloud cover. "Time of day" corresponds to Mountain Daylight Time. Initial values for $T_{b}, T_{a}$, and $T_{s u b}$ at 0630 on 29 June were $3.5,4.0$, and $2.9^{\circ} \mathrm{C}$, respectively. Final values at the end of the test at 0630 on $30 \mathrm{June}$ were $1.0^{\circ} \mathrm{C}\left(T_{b}\right), 0.5^{\circ} \mathrm{C}\left(T_{a}\right)$, and $1.5^{\circ} \mathrm{C}\left(T_{s u b}\right)$. Measurements were made at an altitude of $3050 \mathrm{~m}$ near Gothic, Gunnison County, Colorado

Fig. 4. The relations of oral body temperatures $\left(T_{b}\right)$ of Bufo boreas halophilus to air temperature $\left(T_{a}\right)$ measured at ground level and to substrate temperature $\left(T_{\text {sub }}\right)$ at the point of capture of the toad. Measurements were made at the Devil's Gate Reservoir, La Canada, Los Angeles County, California. The data presented here represent only a portion of the total number of values collected, but the relations of $T_{b}$ to $T_{a}$ and $T_{\text {sub }}$ shown here do not differ significantly from that of the total sample. The diagonal line in the middle of each graph marks equivalency between $T_{b}$ and $T_{a}$ or $T_{s u b}$. The least squares regression equation best describing the relation of $T_{b}$ to $T_{a}$ for all data is: $T_{b}=8.37+0.519 T_{a}(n=131)$. The slope of that equation differs significantly from $\mathrm{I}$. The equation best describing the relation of $T_{b}$ to $T_{s u b}$ is: $T_{b}=0.12+1.00 T_{s u b}(n=131)$

\section{Telemetry of Body Temperatures of Bufo b. boreas}

Body temperatures of a 52.1-g adult female fluctuated between 1 and $32.1^{\circ} \mathrm{C}$ over a 24 -h period (Fig. 3). Her $T_{b}$ was $3.5^{\circ} \mathrm{C}$ at the start of the test at $0630 \mathrm{~h}$ on 29 June. When direct sunlight hit the enclosure, $T_{b}$ increased at a rate averaging $0.19^{\circ} \mathrm{C} / \mathrm{min}$ during the first hour. Body temperatures remained between 27 and $32.1^{\circ} \mathrm{C}$ from approximately 0945 to $1535 \mathrm{~h}$. Short periods of cloud cover had a more dramatic effect on $T_{a}$ and $T_{s u b}$ than on $T_{b}$. During prolonged periods of cloud cover, such as that commencing at $1535 \mathrm{~h}, T_{b}$ dropped from 31 to $21^{\circ} \mathrm{C}$ in $1 \mathrm{~h}$. Body temperature decreased at an average rate of $0.12^{\circ} \mathrm{C} / \mathrm{min}$ during the first hour after sundown. 
Table 1. Twenty-four-h telemetry studies of body temperatures $\left(T_{b}\right)$ of adult Bufo boreas boreas. Six values for rates of increase or decrease in $T_{b}$ over $10-\mathrm{min}$ periods were averaged to obtain the mean rate of warming (in the first hour after direct sunlight hit the enclosure after sunrise) and cooling (in the first hour following sunset) for each individual

\begin{tabular}{|c|c|c|c|c|c|c|}
\hline Date ${ }^{a}$ & Sex & $\begin{array}{l}\text { Body mass } \\
\text { (g) }\end{array}$ & $\begin{array}{l}\text { Minimum } \\
T_{b} \\
\left({ }^{\circ} \mathrm{C}\right)\end{array}$ & $\begin{array}{l}\text { Maximum } \\
T_{b} \\
\left({ }^{\circ} \mathrm{C}\right)\end{array}$ & $\begin{array}{l}\text { Mean } \pm \mathrm{SE} \\
\text { rate of warming } \\
\left({ }^{\circ} \mathrm{C} / \mathrm{min}\right)\end{array}$ & $\begin{array}{l}\text { Mean } \pm S E \\
\text { rate of cooling } \\
\left({ }^{\circ} \mathrm{C} / \mathrm{min}\right)\end{array}$ \\
\hline 11-12 Aug. & 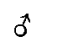 & 26.2 & 6.0 & 32.0 & $0.17 \pm 0.01$ & $0.10 \pm 0.05$ \\
\hline 30 Jun.-1 Jul. & 0 & 32.5 & 0.5 & 31.5 & $0.23 \pm 0.04$ & $0.06 \pm 0.02$ \\
\hline $2-3 \mathrm{Jul}$ & $0^{*}$ & 34.2 & 3.2 & 30.0 & $0.18 \pm 0.02$ & $0.09 \pm 0.04$ \\
\hline 29-30 Jun. & 우 & 52.1 & 1.0 & 32.1 & $0.19 \pm 0.03$ & $0.12 \pm 0.02$ \\
\hline 1-2 Aug. & 9 & 63.7 & 5.2 & 30.5 & $0.15 \pm 0.01$ & $0.10 \pm 0.04$ \\
\hline 10-11 Aug. & q & 82.7 & 7.0 & 27.5 & $0.16 \pm 0.01$ & $0.11 \pm 0.03$ \\
\hline 2-3 Jul. ${ }^{b}$ & 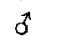 & 34.2 & 2.6 & 30.4 & - & - \\
\hline $2-3 \mathrm{Jul} .^{\mathrm{c}}$ & 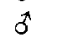 & 31.4 & 2.8 & 27.7 & - & - \\
\hline
\end{tabular}

a All observations made in 1973 except 29-30 June and 30 June-1 July 1974

b Oral $T_{b}$ only, no telemetry device implanted. Toad restricted to enclosure similar to the ones used in all other tests

c Oral $T_{b}$ only, no telemetry device implanted. Toad not restricted to enclosure

Pertinent data for this toad are compared in Table 1 with those for 5 other toads obtained in similar 24-h tests. Body temperatures of these latter individuals fluctuated $20.5-30.0^{\circ} \mathrm{C}$ over the 24 -h tests periods. The variation in $T_{b}$ recorded for males and females is similar. Rates of heating and cooling were not significantly correlated with body mass because the data were collected under different weather conditions. Each toad heated faster than it cooled because solar radiation was intense in the early morning hours.

Implantation of the telemetry device appeared not to affect the range of $T_{b}$ evident in toads. Telemetered $T_{b}$ of a male toad recorded on July $2-3$, 1974, closely approximated the oral $T_{b}$ obtained concurrently from another male toad in a similar enclosure. However, containment in an enclosure might result in higher daytime $T_{b}$ than those which the toads might attain if they were unconfined. Oral $T_{b}$ of a free-ranging male were similar to telemetered $T_{b}$ collected simultaneously at night. However, the daytime maximum was about $2.3^{\circ} \mathrm{C}$ lower than comparable telemetered daytime values.

\section{Body Temperatures of Active Bufo boreas halophilus}

Adult halophilus appear to be primarily nocturnal when not breeding, occupying burrows during the day. However, they are active both nocturnally and diurnally during the breeding season. Body temperatures of breeding adults range between 8.5 and $25.6^{\circ} \mathrm{C}$ with a mean $\pm \mathrm{SE}$ of $17.33 \pm 0.36^{\circ} \mathrm{C}$ for 131 measurements. The toads in this population are rarely active on nights when $T_{a}$ fall below $10^{\circ} \mathrm{C}$. On sunny and warm days the toads usually occupy their burrows or submerge themselves in deep water as $T_{b}$ exceed approximately $25^{\circ} \mathrm{C}$. Body 

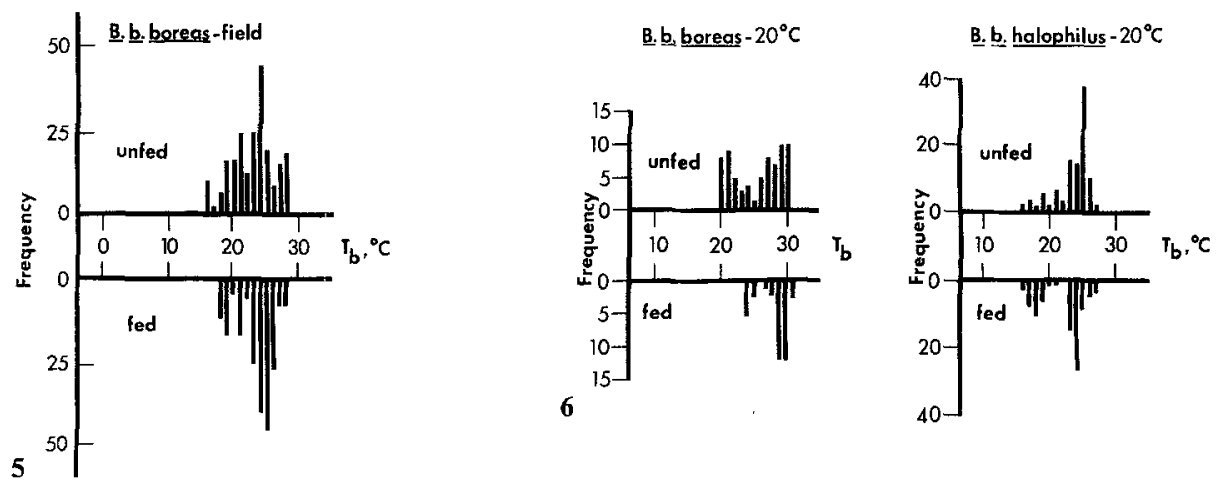

Fig. 5. Frequency distribution of body temperatures $\left(T_{b}\right)$ of unfed (post-absorptive) and recently fed Bufo boreas boreas in a thermal gradient. Toads were maintained under natural conditions of photoperiod and temperature at the Rocky Mountain Biological Laboratory, Gothic, Gunnison County, Colorado

Fig. 6. Frequency distribution of body temperatures $\left(T_{b}\right)$ of unfed (post-absorptive) and recently fed Bufo boreas boreas and halophilus. Animals had been acclimated to $20^{\circ} \mathrm{C}$ for at least one month before testing in a thermal gradient

temperatures of halophilus correlate significantly $(P<0.01)$ with air and substrate temperatures (Fig. 4). Since most of the toads were captured in the water, $T_{b}$ is more highly correlated with $T_{\text {sub }}(r=0.95)$ than with $T_{a}(r=0.73)$.

\section{Thermal Preference}

Fasting boreas that had been maintained under natural conditions attained $T_{b}$ averaging $23.5 \pm 0.23^{\circ} \mathrm{C}( \pm \mathrm{SE})$ in a thermal gradient. After they were fed, their temperatures averaged $24.2 \pm 0.18^{\circ} \mathrm{C}( \pm \mathrm{SE})$, a value slightly but significantly higher $(P<0.01)$ than that for unfed toads. The ranges of $T_{b}$ for unfed and replete toads were 15.8 to $30.2^{\circ} \mathrm{C}$ and 18.0 to $29.2^{\circ} \mathrm{C}$, respectively (Fig. 5). The variance of the preferred $T_{b}$ for fed toads was significantly smaller $(P<0.01)$ than that for fasting toads, as judged by an $F$-test. Individual variation of $T_{b}$ was small compared to the total variation for the group. For instance, two animals respectively selected mean $( \pm \mathrm{SE}) T_{b}$ of $24.4 \pm 0.18^{\circ} \mathrm{C}$ (range 20.0 to $25.6^{\circ} \mathrm{C}$ ) and $23.2 \pm 0.21^{\circ} \mathrm{C}$ (range 21.0 to $24.9^{\circ} \mathrm{C}$ ).

Implantation of the thermocouple had little influence on the level of thermal preference. The mean $\pm \mathrm{SE}$ oral $T_{b}$ of 10 fasted individuals placed in the thermal gradient without an implanted thermocouple was $23.7 \pm 0.30^{\circ} \mathrm{C}$, a value not significantly different from that of toads with thermocouples. Significantly higher values for post-prandial toads appeared to be a response to feeding rather than the amount of time in the gradient. Two individuals placed in the gradient for $48 \mathrm{~h}$ without feeding selected mean $\pm \mathrm{SE} T_{b}$ in the second $24 \mathrm{~h}\left(22.4 \pm 0.42^{\circ} \mathrm{C}\right)$ which were not significantly different from the mean $( \pm S E)$ values recorded during the first $24 \mathrm{~h}\left(22.1 \pm 0.34^{\circ} \mathrm{C}\right)$. 
Table 2. Mean \pm SE evaporative water loss (EWL), body and skin temperature, and experimental conditions of Bufo boreas boreas and Bufo boreas halophilus tested at wind speed of $0.60 \mathrm{~m} / \mathrm{s}$. Sample sizes are indicated by numbers in parentheses

\begin{tabular}{llll}
\hline & $10^{\circ} \mathrm{C}$ & $20^{\circ} \mathrm{C}$ & $30^{\circ} \mathrm{C}$ \\
\hline EWL mg $(\mathrm{g} \cdot \mathrm{h})^{-1}$ & & & \\
$\quad$ B. b. boreas & $11.79 \pm 0.91(6)$ & $21.74 \pm 1.30(6)$ & $34.53 \pm 1.9(6)$ \\
$\quad$ B. b. halophilus & $9.55 \pm 0.40(6)$ & $27.20 \pm 1.70(6)$ & $38.57 \pm 2.9(6)$ \\
Skin temp. $\left({ }^{\circ} \mathrm{C}\right)$ & & & \\
B. b. boreas & $7.45 \pm 0.14(30)$ & $16.65 \pm 0.08(30)$ & $25.11 \pm 0.09(30)$ \\
B. b. halophilus & $7.34 \pm 0.08(30)$ & $16.72 \pm 0.14(30)$ & $25.09 \pm 0.09(30)$ \\
Oral $T_{b}$ ( $\left.{ }^{\circ} \mathrm{C}\right)$ & & & \\
B. b. boreas & & $17.21 \pm 0.27(6)$ & $25.38 \pm 0.17(6)$ \\
B. b. halophilus & $7.48 \pm 0.11(6)$ & $17.58 \pm 0.11(6)$ & $25.88 \pm 0.19(6)$ \\
$T_{a}\left({ }^{\circ} \mathrm{C}\right)$ & $7.65 \pm 0.07(6)$ & & \\
B. b. boreas & & $19.97 \pm 0.19(30)$ & $29.44 \pm 0.01(30)$ \\
B. b. halophilus & $9.79 \pm 0.11(30)$ & $20.40 \pm 0.08(30)$ & $29.45 \pm 0.01(30)$ \\
Dew point $\left({ }^{\circ} \mathrm{C}\right)$ & $9.89 \pm 0.09(30)$ & & $23.0-23.6^{\circ} \mathrm{C}$ \\
B. b. boreas & & $13.6-14.2^{\circ} \mathrm{C}$ & $23.0-23.6^{\circ} \mathrm{C}$ \\
B. b. halophilus & $4.0-4.8^{\circ} \mathrm{C}$ & $13.6-14.2^{\circ} \mathrm{C}$ & \\
\hline
\end{tabular}

Fasted boreas acclimated to $20^{\circ} \mathrm{C}$ had $T_{b}$ averaging $26.2 \pm 0.44^{\circ} \mathrm{C}( \pm \mathrm{SE})$, whereas the preference of fed individuals showed a significantly $(P<0.01)$ higher mean of $29.3 \pm 0.36^{\circ} \mathrm{C}$. The range of temperatures selected decreased from $20.0-30.3^{\circ} \mathrm{C}$ for fasted individuals to $24.9-31.5^{\circ} \mathrm{C}$ for fed toads (Fig. 6). The variances of values for fed toads were significantly smaller $(P<0.01)$. The means for both fed and unfed boreas acclimated to $20^{\circ} \mathrm{C}$ are significantly $(P<0.01)$ higher than respective values for fed and fasted toads maintained under field conditions.

Unfed halophilus, acclimated to $20^{\circ} \mathrm{C}$, selected temperatures averaging $23.9 \pm 0.26^{\circ} \mathrm{C}( \pm \mathrm{SE})$, a value not significantly different from the mean for fed toads, $23.2 \pm 0.38^{\circ} \mathrm{C}$ (Fig. 6). The variance for fed toads is significantly larger $(P<0.01)$ than for unfed toads. The mean of temperatures selected by fasted halophilus was not significantly different from that for unfed boreas maintained under field conditions, but the values for replete boreas are significantly higher $(P<0.01)$ than those for fed halophilus. Mean $T_{b}$ for both fasted and replete halophilus are significantly lower than similar ones for boreas acclimated to $20^{\circ} \mathrm{C}$.

\section{Evaporative Water Loss}

Evaporative water losses (EWL) of boreas and halophilus increase directly with skin temperature when measured under constant conditions of windspeed and relative humidity. The mean $\pm \mathrm{SE} E W L$ of boreas increased from $11.8 \pm 0.9 \mathrm{mg}$ $(\mathrm{g} \cdot \mathrm{h})^{-1}$ at skin temperatures averaging $7.45^{\circ} \mathrm{C}$ to $34.5 \pm 1.9 \mathrm{mg}(\mathrm{g} \cdot \mathrm{h})^{-1}$ at a mean skin temperature of $25.11^{\circ} \mathrm{C}$. Those of halophilus increased from $9.5 \pm 0.4$ 

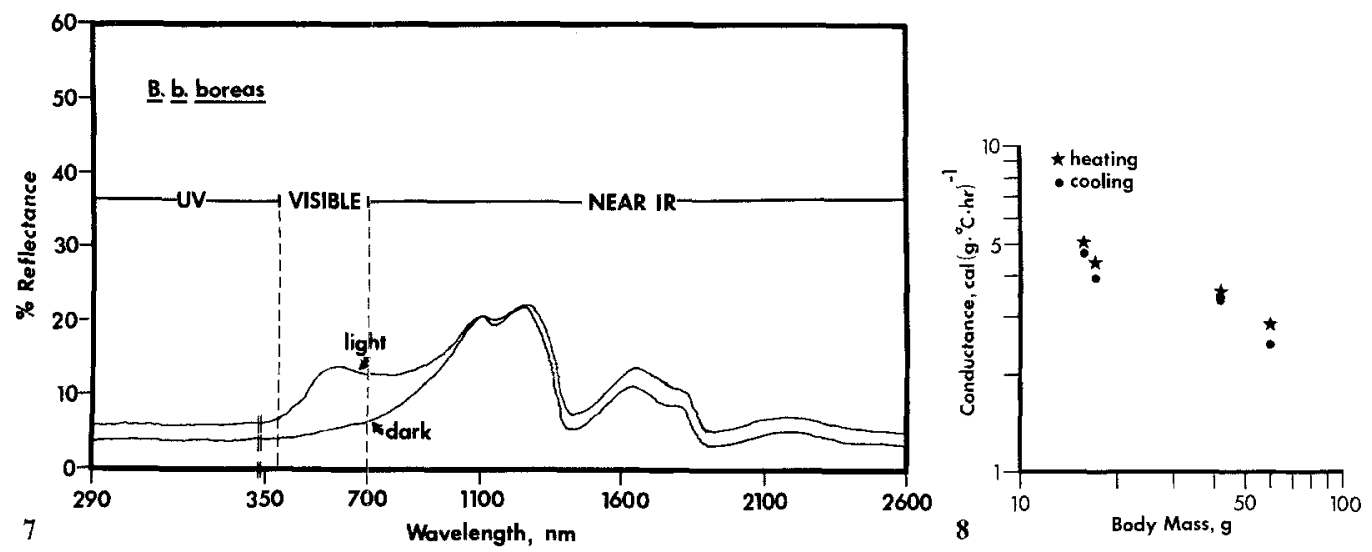

Fig. 7. Reflectance of various wavelengths by the light and dark colored skins of live Bufo boreas boreas. The values indicate the percent reflectance of monochromatic light of the same intensity at all wavelengths

Fig. 8. Relation of apparent conductance $\left(k_{0}\right)$ to body mass in 4 Bufo boreas boreas under conditions of heating and cooling. The values are plotted on a double logarithmic grid

to $38.6 \pm 2.9 \mathrm{mg}(\mathrm{g} \cdot \mathrm{h})^{-1}$ at similar temperatures (Table 2). Only at $20^{\circ} \mathrm{C}$ do the respective means for boreas and halophilus differ significantly $(P<0.01)$. Skin and deep body temperatures were consistently lower than air, wall, and roof temperatures.

\section{Absorption of Solar Radiation}

The reflectance curves for wavelengths of $290-2600 \mathrm{~nm}$ for a typically dark and a light-skinned boreas are shown in Figure 7. The principal differences between the curves are in the visible and near infrared wavelengths. The light skin reflects up to $12 \%$ of the radiation in the visible range, whereas the dark skin reflects from 4 to $6 \%$ in the same range $(400-700 \mathrm{~nm})$. The differences in the curves in the UV and near infrared are in part an artifact due to a greater amount of water on the surface of the light-skinned toad. The dips in the infrared at $1150,1400,1950$, and $2400 \mathrm{~nm}$ are due to water absorption bands. Analysis of the entire reflectance curves by the program of McCullough and Porter (1971) reveals that the dark toad would absorb $92 \%$ and the light toad $88 \%$ of the total incident solar radiation on a clear, dustless day at $1200 \mathrm{MST}$ on 21 June at $3000 \mathrm{~m}$ elevation and the geographical location of Gothic, Colorado.

A typically light colored skin of halophilus reflected between 6 and $21 \%$ of the radiation in the visible range. This skin would absorb $83 \%$ of the total incident solar radiation at the geographical location and altitude of Los Angeles, California on a clear, dustless day at 1200 PST on 31 March. 
Table 3. Estimated $( \pm \mathrm{SE})$ initial body temperatures $\left(T_{b}{ }^{i}\right)$, equilibrium body temperatures $\left(T_{b}^{e q}\right)$, and time constants $(\tau)$ predicted by the program Newton II (Bakken, 1976) for Bufo boreas boreas of different body masses during heating and cooling

\begin{tabular}{|c|c|c|c|c|c|c|c|}
\hline \multirow{2}{*}{$\begin{array}{l}\text { Body } \\
\text { mass }\end{array}$} & \multirow{2}{*}{$\begin{array}{l}\text { Heating } \\
T_{b}{ }^{i} \\
\left({ }^{\circ} \mathrm{C}\right)\end{array}$} & \multirow[b]{2}{*}{$\begin{array}{l}T_{b}^{e q} \\
\left({ }^{\circ} \mathrm{C}\right)\end{array}$} & \multirow[b]{2}{*}{$\begin{array}{l}\tau \\
\text { (s) }\end{array}$} & \multicolumn{3}{|l|}{ Cooling } & \multirow{2}{*}{$\begin{array}{l}\text { Cooling } \tau \\
\text { Heating } \tau\end{array}$} \\
\hline & & & & $\begin{array}{l}T_{b}^{i} \\
\left({ }^{\circ} \mathrm{C}\right)\end{array}$ & $\begin{array}{l}T_{b}{ }^{e q} \\
\left({ }^{\circ} \mathrm{C}\right)\end{array}$ & $\begin{array}{l}\tau \\
(\mathrm{s})\end{array}$ & \\
\hline 15.74 & $7.07 \pm 0.13$ & $19.90 \pm 0.07$ & $579.05 \pm 15.43$ & $20.42 \pm 0.11$ & $7.30 \pm 0.07$ & $614.70 \pm 14.42$ & 1.06 \\
\hline 17.00 & $7.26 \pm 0.16$ & $20.07 \pm 0.22$ & $648.00 \pm 34.08$ & $20.43 \pm 0.09$ & $7.30 \pm 0.09$ & $703.64 \pm 16.64$ & 1.08 \\
\hline 41.32 & $7.61 \pm 0.11$ & $21.28 \pm 0.10$ & $830.92 \pm 27.11$ & $20.90 \pm 0.09$ & $6.77 \pm 0.09$ & $874.73 \pm 22.94$ & 1.05 \\
\hline 60.13 & $7.61 \pm 0.05$ & $21.28 \pm 0.07$ & $1034.37 \pm 15.94$ & $20.90 \pm 0.20$ & $6.77 \pm 0.55$ & $1215.24 \pm 68.03$ & 1.17 \\
\hline
\end{tabular}

\section{Relation of Rates of Heating and Cooling to Body Mass}

The change in $T_{b}$ of 4 toads measured under controlled conditions of radiant heat load, wind speed, dew point, and environmental temperatures were analyzed by the Newton II program (Bakken, 1976a). This program provided estimates of the initial $T_{b}\left(T_{b}^{i}\right)$, the end point of the cooling curve (the final equilibrium temperature, $T_{b}{ }^{e q}$ ) and $\tau$, the constant defining the time for the $T_{b}$ to reach $63 \%$ of the total response $\left(T_{b}{ }^{e q}\right)$ to thermal change for each toad (Table 3 ). As might be anticipated, toads with larger body masses heated and cooled more slowly than did smaller toads. Every animal heated more rapidly than it cooled. The ratios of the time constants for cooling to heating for each toad fell between 1.05 and 1.17. An approximation of the thermal conductance $\left(K_{o}\right)$ can be obtained by dividing the specific heat [taken as $0.82 \mathrm{cal}\left(\mathrm{g} \cdot{ }^{\circ} \mathrm{C}\right)^{-1}$ on the basis of the value for mice, Hart, 1951] by $\tau$. These approximations, shown in Figure 8 for each animal, represent apparent $K_{o}$, as they have not been corrected for metabolic rate and EWL, both of which vary with $T_{b}$ in toads (Table 2; Carey, unpubl. data). This variation results in a difference between measured and actual values of $K_{o}$ (see Bakken and Gates, 1975; Bakken, 1976a). The dorsal skins of the anesthetized toads dried considerably during the course of the experiment, presumably due to the lack of adequate circulation. Calculation of the correction for EWL is thus hindered by the fact that the toads were not evaporating water from a totally saturated surface for the duration of the test. The absence of normal levels of respiratory and circulatory functions in the anesthetized animals undoubtedly minimized the contribution of metabolism to the rates of heating and cooling.

The relation of conductance, $K_{o}$ in cal $\left(\mathrm{g} \cdot{ }^{\circ} \mathrm{C} \cdot \mathrm{h}\right)^{-1}$ to body mass, $W$ in $\mathrm{g}$, for heating appears linear on a double log grid and is best described by the equation calculated by the method of least squares:

$$
\begin{array}{r}
\log \left(K_{o}\right)=1.11-0.36(\log W) \\
{[n=4 \text { SE of slope }=0.06]}
\end{array}
$$

and for cooling: 
$\log \left(K_{o}\right)=1.12-0.40(\log W)$

$[n=4 \mathrm{SE}$ of slope $=0.10]$.

As a result of the large error estimates and small sample sizes, analysis of covariance indicates that the slopes and the intercepts of these equations do not differ significantly. However, it should be noted that each animal served as its own control and heated faster than it cooled.

Skin temperatures at the beginning of the heating test were $0.15-0.25^{\circ} \mathrm{C}$ lower than deep body temperatures. With application of radiant heat load, skin temperatures rapidly exceeded $T_{b}$. Skin temperatures fell below $T_{b}$ within $10 \mathrm{~min}$ in the smaller toads $(15.7$ and $17.5 \mathrm{~g})$ but remained $1-2^{\circ} \mathrm{C}$ higher than $T_{b}$ for the duration of the test in the larger toads $(41.3$ and $61.2 \mathrm{~g}$ ).

\section{Discussion}

\section{Range and Level of $T_{b}$ in Nature}

Body temperatures of boreal toads (Bufo b. boreas) can fluctuate $20-30^{\circ} \mathrm{C}$ over 24-h periods in the field (Table 1 ) and $T_{b}$ can drop $10^{\circ} \mathrm{C}$ in $1 \mathrm{~h}$ (Fig. 3) when weather conditions change. These data are consistent with observations on other montane Bufo. Bufo boreas halophilus are active at $T_{b}$ as low as $3.0^{\circ} \mathrm{C}$ near the upper altitudinal limit of their distribution (Mullally, 1952). Temperatures of active Bufo canorus in the Sierras have been recorded from $2.2^{\circ} \mathrm{C}$ (Karlstrom, 1962) to $30.6^{\circ} \mathrm{C}$ (Mullally and Cunningham, 1956). Bufo spinulosus at $4300 \mathrm{~m}$ in Peru show diurnal fluctuations in $T_{b}$ from 2 to approximately $25^{\circ} \mathrm{C}$ (Pearson and Bradford, 1976).

Although lowland Bufo may experience this range in $T_{b}$ on a yearly basis, the daily range of $T_{b}$ of montane toads appears substantially greater than that of lowland toads. Behavior of montane toads appears to differ in two major respects from that of lowland toads. First, they appear to be voluntarily active over a wider range of $T_{b}$ than lowland toads. During breeding, Bufo boreas halophilus sought deep water or the protection of their burrows if $T_{b}$ fell much below $10^{\circ} \mathrm{C}$ or rose above $25^{\circ} \mathrm{C}$. When they become primarily nocturnal after breeding, they are probably exposed to a narrower daily range of $T_{b}$ than during breeding since their burrows would protect them from high daytime temperatures. A northern population of Bufo woodhousei fowleri was active between 13 and $32^{\circ} \mathrm{C}$ (Hadfield, 1966) and breeding choruses were not noted below $19^{\circ} \mathrm{C}$ in a southern population of Bufo fowleri (Martof, 1962). Individuals of Bufo americanus were active from 17.5 to $32.3^{\circ} \mathrm{C}$ (Fitch, 1956). "Maximum" and "minimum voluntary" $T_{b}$ of individuals of several other lowland Bufo fell between 11.2 and $33.7^{\circ} \mathrm{C}$ (Brattstrom, 1963).

Secondly, diurnal activity, including sitting in direct sunlight, is a typical feature of the behavior of montane toads. Although extensive diurnal activity has been documented for post-metamorphic juveniles of Bufo debilis (Seymour, 1972), Bufo b. boreas (Black and Black, 1969; Lillywhite, 1974), Bufo boreas halophilus (Lillywhite et al., 1973) and Bufo americanus (Fitch, 1956), only occa- 
sional diurnal activity has been noted for adult Bufo of certain lowland populations (Stebbins, 1951; Fitch, 1956; Karlstrom, 1962; Hadfield, 1966). As noted above, individuals of the lowland population of Bufo boreas halophilus used in this study were diurnally active only during breeding.

Diurnality enables montane toads to attain a higher level of $T_{b}$ than if they were strictly nocturnal. However, such behavior also exposes them to a number of hazards, such as diurnal predators, relatively intense UV radiation, and the danger of desiccation on hot, dry substrates. Daily activity over such a broad range of temperatures may also require the development of extensive capacities for metabolic regulation. Such regulation could well be important to maintenance of the functional integrity of the organism at all $T_{b}$, particularly during sudden decreases or increases in $T_{b}$. Finally, the capacity for activity over a very broad range of temperatures may have obviated establishing optimal function over a narrow range of $T_{b}$. If any of these hazards posed substantial problems for toads invading montane areas, compelling benefits must have existed favoring selection for diurnal behavior.

The simplest explanation for extensive diurnality in montane toads could be that their food may be active primarily at warm, daytime temperatures. Most of the principal food sources of boreas are diurnally active, especially during warm, sunny periods (Carey, unpubl. data). In addition, the action of the tongue in feeding is very slow at low $T_{b}$ (Carey, unpubl. data). Cold and the availability of prey do not completely exclude nocturnal feeding by toads, but they seem to favor these animals' seeking warm places, especially those in the sun. Therefore, the high daytime $T_{b}$ of montane toads may simply be a by-product of food-seeking. Another explanation for diurnal behavior is that optimal function of some physiological processes may require high $T_{b}$, as in reptiles (see reviews by Dawson, 1975; Bennett and Dawson, 1976). Warm $T_{b}$ may be necessary to obtain and digest enough food for growth and reproduction in the short period of activity each year. The requirements of high $T_{b}$ for rapid growth and digestion have been suggested in juvenile Bufo boreas halophilus (Lillywhite et al., 1973), Bufo debilis (Seymour, 1972), and adult Bufo woodhousei fowleri (Hadfield, 1966).

\section{Behavioral Thermal Preferences}

Both food-seeking at warm temperatures and basking behaviors require the ability to measure thermal parameters. Studies of behavior of amphibians in thermal gradients have demonstrated that this group clearly has the capacity to discriminate among a variety of substrate or water temperatures. Larvae (Brattstrom, 1962; Lucas and Reynolds, 1967; Herreid and Kinney, 1967; Licht and Brown, 1967) and post-metamorphic individuals (Rosenthal, 1957; Lillywhite, 1971; Cabanac and Jeddi, 1971; Lillywhite et al., 1973; Duclaux et al., 1973) can confine $T_{b}$ to a narrow range in thermal gradients. The mechanism underlying this capacity to detect environmental temperatures and to select not only a characteristic level but also a narrow range of $T_{b}$ are poorly understood. Although some peripheral receptors may be involved (Cabanac and Jeddi, 
1971), the central nervous system appears to be the primary site of thermal measurement and direction of behavioral temperature selection (Lillywhite, 1971; Duclaux et al., 1973).

Bufo $b$. boreas held under field conditions select body temperatures in a thermal gradient that lie near the warmer levels of $T_{b}$ at which they are active in the field. Unlike certain reptiles (Regal, 1967), boreas and halophilus do not preferentially select cooler $T_{b}$ in a thermal gradient during the dark portion of the photoperiod. Therefore, the cooler $T_{b}$ at which these toads are active at night are an exclusive function of the cold $T_{a}$ of their environment.

The level of preferred temperature of boreas can be altered by several factors. The mean preferred $T_{b}$ of recently fed boreal toads maintained under field conditions was significantly higher than that for unfed toads. However, the difference in the means $\left(0.7^{\circ} \mathrm{C}\right)$ appears of minimal biological importance, especially considering the wide range of $T_{b}$ within which the toads normally operate. Recent feeding increases the amount of time spent basking in the field (Regal, 1966; Moll and Legler, 1971) and the level of preferred $T_{b}$ in thermal gradients in certain reptiles (Gatten, 1974) and juvenal anurans (Lillywhite et al., 1973). However, it appears to have little effect on preferred $T_{b}$ in other reptiles (Gatten, 1974; Diefenbach, 1975) and adult anurans (Lillywhite, 1971). The fact that neither boreas under field conditions nor halophilus acclimated to $20^{\circ} \mathrm{C}$ selected distinctly higher $T_{b}$ following feeding suggests that basking or seeking warm $T_{b}$ may have little functional significance for digestion. Since adult halophilus are principally nocturnal, it is unlikely that strong selection for thermophilic behavior following feeding has occurred. Indeed, one disadvantage of higher $T_{b}$ to boreas following feeding is the reduction of absorptive efficiency, which declines with relatively rapid passage of food through the digestive tract at higher $T_{b}$ (Carey, unpubl, data). It should be noted that none of the field-collected boreal toads dissected during the course of the study had an empty stomach or intestine (Carey, unpubl. data). Therefore, the toads are operating in the field almost exclusively in the "fed" condition.

Acclimation to $20^{\circ} \mathrm{C}$ has a pronounced effect on the thermal preference of boreal toads. This is not without precedent, acclimation having been shown to alter the level of preferred $T_{b}$ in some other anurans (Lucas and Reynolds, 1967; Lillywhite, 1971), fishes (Norris, 1963), and lizards (Wilhoft and Anderson, 1960). However, such effects are not universal, judging by results obtained from certain salamanders (Licht and Brown, 1967) and lizards (Licht, 1968). Further data on preferred $T_{b}$ of boreal toads acclimated to a variety of constant and fluctuating temperature regimes are needed to determine the reason for the difference in the response between the acclimated toads and individuals held under field conditions. The data do suggest that caution should be applied in the extrapolation of preferred levels of acclimated toads to preferred levels for activity in the field.

Although the physiological significance of preferred levels of $T_{b}$ in reptiles is becoming well characterized (see review by Dawson, 1975), insufficient correlations between preferred level and physiological performance are available to permit satisfactory analysis of the functional importance of such preference for amphibians. The importance is particularly obscure for boreas where the 
attainment of preferred levels each day may be restricted by environmental circumstances. Although many of the $T_{b}$ taken orally in free-ranging boreal toads in the field fall close to the preferred level of $T_{b}$, telemetric data (Fig. 3) indicate that under some conditions $T_{b}$ may exceed preferred levels by as much as 7 to $8^{\circ} \mathrm{C}$ for 5 to $7 \mathrm{~h}$. Activity of reptiles at $T_{b}$ above preferred levels has been attributed to the lack of a suitable heat sink or to the exchange of thermal "comfort" for additional time above the surface to defend territories (Licht et al., 1966; DeWitt, 1967 a, b; Bradshaw and Main, 1968). These explanations may not apply adequately to the activity of boreas above preferred levels of $T_{b}$. First, these toads wander widely and do not appear to defend feeding territories. Second, boreal toads do have suitable heat sinks available in the shade, where temperatures rarely reach $25^{\circ} \mathrm{C}$. Although toads are often found in the shade, most individuals (with the exception of females living on dry hillsides) do not use burrows or cavities beneath rocks or logs except during hail and snow storms, and nights with subfreezing temperatures. Similarly, the behavior of these toads differs from that of certain reptiles in that they are active at night and on cloudy days much below their preferred levels of $T_{b}$. Therefore, the capacity of this group for selecting temperatures in a thermal gradient may relate more to their capacity to note variability in environmental temperatures, to avoid lethal temperatures, and to select appropriate temperatures at which prey are likely to be active, rather than to direct behavior for activity over a narrow range.

\section{Evaporative Water Loss}

Certain desert reptiles can maintain fairly constant $T_{b}$ during portions of the day by shuttling between heat sources, such as direct sunlight, and heat sinks, such as shade or burrows (DeWitt, 1967a, b). When sunlight is continuously available during midday, telemetered $T_{b}$ of boreal toads vary only $4-6^{\circ} \mathrm{C}$ for several hours (Fig. 3). Since the toads were not observed during the telemetry

Table 4. Determination of a thermal budget of a toad (Part A) and estimation of parameters used in the budget (Part B). Toad, weighing $40 \mathrm{~g}$, is sitting in the sun with $T_{b}=28^{\circ} \mathrm{C}, T_{a}=25^{\circ} \mathrm{C}$, wind speed $=60 \mathrm{~cm} / \mathrm{s}$, relative humidity $=80 \%$, on June 22 at noon at the altitude and geographical location of Gothic, Colorado

Part A. Total steady-state thermal budget

$\dot{Q}_{a b s}=\dot{q}_{r a d}+\dot{q}_{c o n v}+\dot{q}_{e v a p}+\dot{q}_{c o n d}+$ work

Total heat gain

$\dot{Q}_{a b s}=S a A_{s i l}=(1.53)(0.88)(39)=52.5 \mathrm{cal} / \mathrm{min}$

Heat loss by radiation

$\dot{q}_{\text {rat }}=F A_{s} \varepsilon \sigma\left(T_{a}^{4}{ }^{4} T_{\text {skin }}{ }^{4}\right)=(0.9)(87.6)\left(8.13 \times 10^{-11}\right)(0.97)\left[(298)^{4}-(301)^{4}\right]=-2.00 \mathrm{cal} / \mathrm{min}$

Heat loss by convection

$\dot{q}_{c o n v}=A_{s} h_{c}\left(T_{a}-T_{s}\right)=(87.64)(0.025)(297-301)=-8.76 \mathrm{cal} / \mathrm{min}$

Heat loss by evaporation

$\dot{q}_{\text {evap }}=L A_{s} h_{D}\left(\rho_{a}-\rho_{s}\right)=(0.582)(87.64)(89.61)[(0.8)(0.02305)-(0.02724)]=-40.22 \mathrm{cal} / \mathrm{min}$ 
Table 4 (continued)

Part B. Estimation of parameters

\begin{tabular}{|c|c|c|}
\hline Parameter & Value & Method of estimation \\
\hline$S$ (total incident radiation) & $\begin{array}{l}1.53 \mathrm{cal} \\
\left(\mathrm{cm}^{2} \cdot \mathrm{min}\right)^{-1}\end{array}$ & Program of McCullough and Porter (1971) \\
\hline $\begin{array}{l}\text { a (absorptivity of light } \\
\text { skinned toad) }\end{array}$ & $88 \%$ & Program of McCullough and Porter (1971) \\
\hline$A_{\text {sil }}$ (silhouette area) & $39 \mathrm{~cm}^{2}$ & $A_{s i l}=0.40 \mathrm{~A}_{\text {total }}($ Tracy, 1972$)$ \\
\hline $\begin{array}{l}A_{\text {total }} \text { (total surface area } \\
\quad \text { of toad) }\end{array}$ & $97.4 \mathrm{~cm}^{2}$ & $A_{\text {total }}=12.39 \mathrm{~W}^{0.559}($ Tracy, 1972$)$ \\
\hline$W$ (body mass) & $40 \mathrm{~g}$ & given \\
\hline$F$ (view factor) & $90 \%$ & (Tracy, 1972) \\
\hline $\begin{array}{l}A_{\text {s }} \text { (area for heat exchange } \\
\text { by all routes other than } \\
\text { conduction) }\end{array}$ & $87.64 \mathrm{~cm}^{2}$ & $A_{s}=A_{\text {total }}-A_{\text {ventral }}($ Tracy, 1972) \\
\hline$A_{\text {ventral }}$ (ventral surface area) & $9.97 \mathrm{~cm}^{2}$ & $A_{\text {ventral }}=0.425 \mathrm{~W}^{0.85}($ Tracy, 1972$)$ \\
\hline$\sigma \quad($ Stefan-Boltzmann constant $)$ & $\begin{array}{l}8.13 \times 10^{-11} \\
\left(\mathrm{~cm}^{2} \cdot \min \cdot \mathrm{T}^{4}\right)^{-1}\end{array}$ & \\
\hline$\varepsilon \quad$ (emmissivity) & 0.97 & (Tracy, 1972) \\
\hline$T_{a}$ (ambient temperature) & $298^{\circ} \mathrm{K}$ & given \\
\hline$T_{\text {skin }}$ (skin temperature) & $301^{\circ} \mathrm{K}$ & assumed to $=T_{b}$ \\
\hline $\begin{array}{l}h_{c} \text { (convective heat transfer } \\
\text { coefficient) }\end{array}$ & $\begin{array}{l}0.025 \mathrm{cal} \\
\left(\mathrm{cm}^{2} \cdot \min \cdot{ }^{\circ} \mathrm{K}\right)^{-1}\end{array}$ & $h_{c}=\frac{N u \cdot k_{a}}{L_{s}}$ \\
\hline$N u$ (Nusselt Number) & 53.81 & $\mathrm{Nu}=0.258 R e^{0.667}($ Tracy, 1972) \\
\hline$R e$ (Reynolds Number) & 3000 & $\operatorname{Re}=\frac{L_{s v} \cdot v}{v}$ \\
\hline$L_{s v}($ snout-vent length $)$ & $7.75 \mathrm{~cm}$ & $L_{s v}=2.68 W^{0.288}($ Tracy, 1972$)$ \\
\hline$k_{a}$ (thermal conductivity of air) & $\begin{array}{l}3.68 \times 10^{-3} \mathrm{cal} \\
\left(\mathrm{cm} \cdot \min \cdot{ }^{\circ} \mathrm{K}\right)^{-1}\end{array}$ & (Monteith, 1973) \\
\hline$v \quad$ (wind velocity) & $60 \mathrm{~cm} / \mathrm{s}$ & given \\
\hline$v \quad$ (kinematic viscosity of air) & $0.155 \mathrm{~cm}^{2}(\mathrm{~s})^{-1}$ & (Monteith, 1973) \\
\hline$L$ (latent heat of evaporation) & $0.582 \mathrm{cal}(\mathrm{mg})^{-1}$ & (Monteith, 1973) \\
\hline$h_{D}$ (mass trasfer coefficient) & $89.61 \mathrm{~cm}(\mathrm{~min})^{-1}$ & $h_{D}=\frac{S h \cdot D}{L_{x}}$ \\
\hline Sh (Sherwood Number) & 45.04 & $0.216 R e^{0.667}$ (Tracy, 1972) \\
\hline $\begin{array}{l}D \text { (diffusion coefficient of } \\
\text { water vapor in air) }\end{array}$ & $\begin{array}{l}15.42 \mathrm{~cm}^{2} \\
(\min )^{-1}\end{array}$ & (Monteith, 1973) \\
\hline $\begin{array}{l}\rho_{a} \text { (vapor density in air } \\
\text { at } 25^{\circ} \mathrm{C} \text { ) }\end{array}$ & $\begin{array}{l}0.02305 \mathrm{mg} \\
\left(\mathrm{cm}^{3}\right)^{-1}\end{array}$ & (Monteith, 1973) \\
\hline $\begin{array}{l}\rho_{s} \text { (vapor density of water } \\
\text { at skin surface temperature } \\
\text { at } 28^{\circ} \mathrm{C} \text { ) }\end{array}$ & $\begin{array}{l}0.02724 \mathrm{mg} \\
\left(\mathrm{cm}^{3}\right)^{-1}\end{array}$ & (Monteith, 1973) \\
\hline
\end{tabular}

test, it is not possible to determine whether the relatively constant $T_{b}$ were due to behavioral shuttling between sunlight and shade or by balancing heat gain from direct sunlight with heat loss by evaporation, convection, and conduction. The ability to remain motionless in the sun for long periods would have obvious benefits for sit-and-wait predators such as toads whose movement would alert prey. Much of the detailed data required for a full calculation of a thermal budget for a toad sitting in the sun are not available, but an extremely simplified budget may be constructed as shown in Table 4. It is assumed for the purpose 
of these calculations that parameters used for the estimation of convection coefficients and anatomical dimensions of Rana pipiens (Tracy, 1972) would be applicable to toads. The standard metabolism of a resting toad at $28^{\circ} \mathrm{C}$, calculated to be $0.016 \mathrm{cal} / \mathrm{min}$ (Carey, unpubl. data) is ignored. These calculations predict that evaporation, radiation, and convection could account for $50.98 \mathrm{cal} /$ $\min$, or $97 \%$ of the total absorbed radiation, leaving $1.52 \mathrm{cal} / \mathrm{min}$, or $3 \%$, to be lost by conduction, assuming that a sitting toad is performing no external work (defined in $\mathrm{cal} / \mathrm{min}$ ). Under these specified conditions, this hypothetical toad could sit in the sun for long periods without overheating, provided that the surface of the skin remains fully saturated. Although much attention has previously focused on the physiological abilities of amphibians for limiting water loss (see reviews of literature by Bentley, 1966; Shoemaker, 1975), none has dealt with abilities for maximizing water loss under conditions of high heat loading. The skin of Bufo poses some resistance to water loss (Machin, 1969). Toads are able to supplement or supplant water loss through the skin by moving water contacted from moist substrate by the ventral surface to the lateral and dorsal areas (Lillywhite and Licht, 1974). Under conditions of rapid evaporation at high skin temperatures and wind speed, such a mechanism might ensure complete saturation of the skin. In addition, evaporation of ground water would reduce the loss of body solute which accompanies evaporation of body water (Campbell et al., 1967).

The high substrate temperatures (up to $42^{\circ} \mathrm{C}$ ), low relative humidity in areas without standing water, and intense solar radiation at high elevations produce conditions which make it unfavorable for montane toads to move away from water or moist substrates for long periods during the day. Some females live some distance from water on dry hillsides. They appear to restrict their activity, remaining near or within a burrow, and rehydrate by traveling to water at night. Most long distance movements by male boreas and montane Bufo spinulosus of both sexes (Pearson and Bradford, 1976) also occur at night. Cold nocturnal temperatures not only eliminate the dangers of overheating, but also reduce EWL at the low skin temperatures and high relative humidities. Therefore, the retention of nocturnal behavior by montane toads allows them to live for extended periods farther away from water than if they were strictly diurnal.

\section{Modification of Rates of Heating and Cooling}

Mechanisms for rapid heating following sunrise or cloud cover and for retarding cooling when solar radiation becomes unavailable might be beneficial if a physiological premium is attached to warm $T_{b}$ for montane toads. One possible mechanism for maximizing the rate of warming is modification of skin color in a manner increasing absorption of solar radiation. Boreas exhibit a wide variety of skin tones, the darker ones more usually associated with colder animals. Bufo spinulosus are also darkly pigmented (Pearson and Bradford, 1976). Analysis of the effect of skin color on rates of heating suggests that a darker toad would not heat appreciably faster than a light toad. The difference in absorbed radiation 
between dark and light skin would be about $2.4 \mathrm{cal} / \mathrm{min}$. Considering the resultant difference in vapor pressure at the surface of the skin, the difference in skin temperature would be approximately $0.34^{\circ} \mathrm{C}$. Even if the darker toad could warm to its equilibrium temperature faster than a light toad, the difference of a few additional minutes at the warm $T_{b}$ may have limited biological importance. The short time at a warm $T_{b}$ would not noticeably benefit the rate of digestion, as it takes 3-4 days for boreas to pass a prey item through its digestive tract at body temperatures fluctuating between 5 and $30^{\circ} \mathrm{C}$ (Carey, unpubl. data). The thermal importance of skin color would be that a lighter toad would reach a lower equilibrium temperature (about $0.5^{\circ} \mathrm{C}$ ) than a darker toad. This may contribute to prevention of overheating.

Large body mass may benefit animals such as Galapagos marine iguanas, Amblyrhynchus cristatus, which bask on land in the sun and then feed in the cold sea. Most terrestrial ectotherms, however, do not experience rapid changes in thermal environment such as they are exposed to in laboratory tests of heating and cooling rates, but rather would track equilibrium $T_{b}$ as their thermal environment heats or cools following sunrise, sunset, etc. In these instances, differences in rates of heating and cooling attributable to body mass observed in the laboratory may have limited importance in the field.

Acknowledgements. This study was supported by an NSF grant for doctoral research in the field sciences (GB-41454), a grant from the Theodore Roosevelt Memorial Fund of the American Museum of Natural History, an NSF grant for the study of Systematics and Evolutionary Biology (GB-25986, Nelson G. Hairston, Principal Investigator), and a Doctoral Dissertation Grant from The Horace H. Rackham School of Graduate Studies of The University of Michigan. Dr. William $R$. Dawson provided laboratory facilities at The University of Michigan and advice and encouragement throughout the course of this study. Laboratory facilities at the Rocky Mountain Biological Laboratory were provided by Dr. John C. Johnson, Jr. Dr. Warren P. Porter and Dr. George S. Bakken supplied training for the use of the spectroreflectometer and apparatus for testing evaporative water loss, respectively. Dr. David M. Gates provided access to laboratory equipment. Critical comments on the manuscript were rendered by G.S. Bakken, W. Buttemer, W.R. Dawson, C. Gans, B.E. Frye, R.L. Marsh, M.M. Martin, and W.P. Porter. I am exceedingly grateful to G.S. Bakken for substantial aid and advice.

\section{References}

Bakken, G.S.: An improved method for determining thermal conductance and equilibrium body temperature with cooling curve experiments. J. Thermal Biol. 6, 169-175 (1976a)

Bakken, G.S.: A heat transfer analysis of animals: unifying concepts and the application of metabolism chamber data to field ecology. J. Theoret. Biol. 60, 337-384 (1976 b)

Bakken, G.S., Gates, D.M.: Heat-transfer analysis of animals: some implication for field ecology, physiology, and evolution. In: Perspectives of biophysical ecology (D.M. Gates, R.M. Schmerl, eds.), pp. 255-290. Berlin-Heidelberg-NewYork: Springer 1975

Bartlett, P.N., Gates, D.M.: The energy budget of a lizard on a tree trunk. Ecology 48, 315-322 (1967)

Bennett, A.F., Dawson, W.R.: Metabolism. In: Biology of the reptilia (C. Gans, W.R. Dawson, eds.), Vol. 5, pp. 127-223. New York: Academic Press 1976

Bentley, P.J.: Adaptations of amphibia to arid environments. Science 152, 619-623 (1966)

Black, J.H., Black, J.N.: Postmetamorphic basking aggregations of the boreal toad, Bufo boreas boreas. Can. Field-Nat. 83, 155-156 (1969) 
Bradshaw, S.D., Main, A.R.: Behavioral attitudes and regulation of temperature in Amphibolurus lizards. J. Zool. (Lond.) 154, 193-221 (1968)

Brattstrom, B.H.: Thermal control of aggregation behavior in tadpoles. Herpetologica 18, 38-46 (1962)

Brattstrom, B.H.: A preliminary review of thermal requirements of amphibians. Ecology 44, 238-255 (1963)

Brett, J.R.: Energetic responses of salmon to temperature. A study of some thermal relations in the physiology and freshwater ecology of sockeye salmon (Oncorhynchus nerka). Am. Zool. 11, 99-113 (1971)

Cabanac, M., Jeddi, E.: Thermopreferendum et thermoregulation comportementale chez trois poikilothermes. Physiol. Behav. 7, 375-380 (1971)

Campbell, J.B.: New elevational records for the boreal toad (Bufo boreas boreas). Arctic Alpine Res. 2, 157-159 (1970)

Campbell, J.P., Aiyawar, R.M., Berry, E.R., Huf, E.G.: Electrolytes in frog skin secretions. Comp. Biochem. Physiol. 23, 213-223 (1967)

Cowles, R.B., Bogert, C.M.: A preliminary study of the thermal requirements of desert reptiles. Bull. Am. Mus. Nat. Hist. 83, 265-296 (1944)

Dawson, W.R.: On the physiological significance of the preferred body temperatures of reptiles. In: Perspectives of biophysical ecology (D.M. Gates, R.B. Schmerl, eds.), pp. 443 473. BerlinHeidelberg-New York : Springer 1975

Diefenbach, C.O. da C.: Thermal preferences and thermoregulation in Caiman crocodilus (Crocodylia: Reptilia). Copeia 1975, 530-540 (1975)

DeWitt, C.B.: Behavioral thermoregulation in the desert iguana. Science 158, $809-810$ (1967a)

DeWitt, C.B.: Precision of thermoregulation and its relation to environmental factors in the desert iguana, Dipsosaurus dorsalis. Physiol. Zool. 40, 49-66 (1967b)

Duclaux,R., Fantino, M., Cabanac, M.: Comportement thermoregulateur chez Rana esculenta. Influence du rechauffement spinal. Pflügers Arch. 342, 347-358 (1973)

Fitch, H.S.: Temperature responses in free-living amphibians and reptiles of northeastern Kansas. Univ. Kansas. Publ. Mus. Nat. Hist. 8, 417-476 (1956)

Gatten, R.E. : Effect of nutritional status on the preferred body temperature of the turtles Pseudemys scripta and Terrepene ornata. Copeia 1974, 912-917 (1974)

Hadfield, S.: Observations on body temperature and activity in the toad, Bufo woodhousei fowleri. Copeia 1966, 581-582 (1966)

Hart, J.S.: Calorimetric determination of average body temperature of small mammals and its variation with environmental conditions. Can. J. Zool. 29, 224-233 (1951)

Heath, J.E.: Temperature regulation and diurnal activity in horned lizards. Univ. Calif. Publ. Zool. 64, 97-136 (1965)

Herreid, C.F., Kinney, S.: Temperature and development of the wood frog, Rana sylvatica, in Alaska. Ecology 48, 579-590 (1967)

Karlstrom, E.L.: The toad genus Bufo in the Sierra Nevada of California. Univ. Calif. Publ. Zool. 61, 1-104 (1962)

Licht, P.: Response of the thermal preferendum and heat resistance to thermal acclimation under different photoperiods in the lizard Anolis carolinensis. Am. Midl. Nat. 79, 149-158 (1968)

Licht, P., Brown, A.G.: Behavioral thermoregulation and its role in the ecology of the red-bellied newt, Taricha rivularis. Ecology 48, 598-611 (1967)

Licht, P., Dawson, W.R., Shoemaker, V.H., Main, A.R.: Observations on the thermal relations of western Australian lizards. Copeia 1966, 97-110 (1966)

Lillywhite, H.B.: Temperature selection by the bullfrog, Rana catesbeiana. Comp. Biochem. Physiol. 40 A, 213-227 (1971)

Lillywhite, H.B.: Comments on a postmetamorphic aggregate of Bufo boreas. Copeia 1974, 984-986 (1974)

Lillywhite, H.B., Licht, P.: Movement of water over toad skin: functional role of epidermal sculpturing. Copeia 1974, 165-171 (1974)

Lillywhite, H.B., Licht, B., Chelgren, P.: The role of behavioral thermoregulation in the growth energetics of the toad, Bufo boreas. Ecology 54, 375-383 (1973)

Lindley, D.V.: Introduction to probability and statistics 248 pp. London: Cambridge 1965 
Lucas, E.A., Reynolds, W.A. : Temperature selection by amphibian larvae. Physiol. Zool. 40, 159-171 (1967)

Machin, J.: Passive water movements through skin of the toad Bufo marinus in air and in water. Am. J. Physiol. 216, 1562-1568 (1969)

Martof, B.S.: The behavior of Fowler's toad under various conditions of light and temperature. Physiol. Zool. 35, 38-46 (1962)

McCullough, E.M., Porter, W.P.: Computing clear day solar radiation spectra for the terrestrial ecological environment. Ecology 52, 1008-1015 (1971)

Moll, E.O., Legler, J.M.: The life history of a neotropical slider turtle Pseudemys scripta (Schoepff) in Panama. Bull. L.A. Co. Mus. Nat. Hist. Sci. 11, 1-102 (1971)

Monteith, J.L.: Principles of environmental physics, 241 pp. London: Arnold 1973

Mullally, D.P.: Habits and minimum temperatures of the toad Bufo boreas halophilus. Copeia 1952, 274-275 (1952)

Mullally, D.P., Cunningham, J.D. : Aspects of the thermal ecology of the Yosemite toad. Herpetologica 12, 57-67 (1956)

Norris, K.S.: The functions of temperature in the ecology of the percoid fish Girella nigricans (Ayres). Ecol. Monogr. 33, 23-62 (1963)

Norris, K.S.: Color adaptation in desert reptiles and its thermal relationships. In: Lizard ecology. A symposium (W.W. Milstead, ed.), pp. 162-229. Columbia: University of Missouri Press 1967

Pearson, O.P., Bradford, D.F.: Thermoregulation of lizards and toads at high altitudes in Peru. Copeia 1976, 155-170 (1976)

Porter, W.P.: Solar radiation through the living body walls of vertebrates with emphasis on desert reptiles. Ecol. Monogr. 37, 273-296 (1967)

Porter, W.P., Gates, D.M. : Thermodynamic equilibria of animals with environment. Ecol. Monogr. 39, 245-270 (1969)

Porter, W.P., Mitchell, J.W., Beckman, W.A., Dewitt, C.B.: Behavioral implications of mechanistic ecology. Thermal and behavioral modeling of desert ectotherms and their microenvironment. Oecologia (Berl.) 13, 1-54 (1973)

Regal, P.J.: Thermophilic response following feeding in certain reptiles. Copeia 1966, 588-590 (1966)

Regal, P.J.: Voluntary hypothermia in reptiles. Science 155, 1551-1553 (1967)

Rosenthal, G.M.: The role of moisture and temperature in the local distribution of the plethodontid salamander Aneides lugubris. Univ. Calif. Publ. Zool. 54, 371-420 (1957)

Seymour, R.S.: Behavioral thermoregulation by juvenal green toads, Bufo debilis. Copeia 1972, $572-575$ (1972)

Shoemaker, V.H.: Adaptations to aridity in amphibians and reptiles. In: Physiological adaptation to the environment (F.J. Vernberg, ed.), pp. 143-154. New York: Intext Educational Publ. 1975

Stebbins, R.C.: Amphibians of western North America, 539 pp. Berkeley: University of California Press 1951

Tracy, C.R.: A model of the water and energy dynamic interrelationships between an amphibian and its environment. $\mathrm{Ph}$. D. Dissertation, University of Wisconsin, 130 pp. (1972)

Tracy, C.R.: Water and energy relations of terrestrial amphibians: insights from mechanistic modeling. In: Perspectives of biophysical ecology (D.M. Gates, R.B. Schmerl, eds.), pp. 325-346, Berlin-Heidelberg-NewYork: Springer 1975

Wilhoft, D.C., Anderson, J.D.: Effect of acclimation on the preferred body temperature of the lizard, Sceloporus occidentalis. Science 131, 610-611 (1960)

Received January 28, 1978 